Glial cell line-derived neurotrophic factor induces proliferation of osteoblastic cells

Zoe Gale, Paul R. Cooper, and Ben A. Scheven

Cytokine

Volume 57, Issue 2, Feb 2012, Pages 276-281

ISSN 1043-4666

DOI: $10.1016 /$ j.cyto.2011.10.023

This is the author's post-print. The published version is available at http://www.sciencedirect.com/science/article/pii/S1043466611008143 


\title{
Glial cell line-derived neurotrophic factor induces proliferation of osteoblastic cells
}

\author{
Zoe Gale, Paul R. Cooper, and Ben A. Scheven \\ School of Dentistry, College of Medical and Dental Sciences, \\ University of Birmingham, Birmingham, U.K.
}

\begin{abstract}
Little is known about the role of neurotrophic growth factors in bone metabolism. This study investigated the short-term effects of glial cell line-derived neurotrophic factor (GDNF) on calvarial-derived MC3T3-E1 osteoblasts. MC3T3-E1 expressed GDNF as well as its canonical receptors, GFR $\alpha 1$ and RET. Addition of recombinant GDNF to cultures in serum-containing medium modestly inhibited cell growth at high concentrations; however, under serum-free culture conditions GDNF dose-dependently increased cell proliferation. GDNF effects on cell growth were inversely correlated with its effect on alkaline phosphatase (ALP) activity showing a significant dose-dependent inhibition of relative ALP activity with increasing concentrations of GDNF in serumfree culture medium. Live/dead and lactate dehydrogenase assays demonstrated GDNF did not significantly affect cell death or survival under serum-containing and serum-free conditions. The effect of GDNF on cell growth was abolished in the presence of inhibitors to GFR $\alpha 1$ and RET indicating that GDNF stimulated calvarial osteoblasts via
\end{abstract}


its canonical receptors. Finally, this study found that GDNF synergistically increased tumor necrosis factor- $\alpha(\mathrm{TNF}-\alpha)$-stimulated MC3T3-E1 cell growth suggesting that GDNF interacted with TNF- $\alpha$-induced signaling in osteoblastic cells. In conclusion, this study provides evidence for a direct, receptor-mediated effect of GDNF on osteoblasts highlighting a novel role for GDNF in bone physiology.

Key words: GDNF, neurotrophic factor, TNF-alpha, osteoblast, bone, calvarial, cell proliferation

\section{Introduction}

Glial cell line-derived neurotrophic factor (GDNF) is a pleiotropic signaling molecule playing a pivotal role in the development and regulation of the nervous system (1-2). GDNF has been recognized as a potent survival factor for neuronal cells in addition to its essential roles in neural migration and differentiation (1-3). GDNF is also widely expressed outside neuronal tissues and has been suggested to be involved in epithelialmesenchymal interactions during development of urogenital and dental tissues (1, 4-6). GDNF is able to elicit various intracellular signalling cascades via multiple receptor systems, primarily through the glycosyl-phosphatidylinositol-anchored, GDNF family receptor $\alpha($ GFR $\alpha 1)$ and the tyrosine kinase transmembrane co-receptor RET (2-3).

Neurotrophic growth factors and cytokines including GDNF have been shown to be expressed in bone marrow stromal cells prompting an emerging interest in therapeutic regenerative application of bone marrow-derived mesenchymal stem cells in neurological disorders (7-11). Interestingly, whilst GFR $\alpha 1$ expression was detected 
along with GDNF in bone marrow stromal cells, RET proved to be absent in these cells (12-13). However, GDNF/GFR $\alpha 1$ complexes cleaved from the stromal cells were shown to elicit functional signaling through RET expressed on hematopoietic and leukemic cells suggesting a signaling pathway involving cell-cell interactions within the bone marrow environment (13-14). In this study we addressed the question whether GDNF may be involved in bone metabolism. In particular, this study focused on the short term effects of GDNF on the proliferation and survival of osteoblastic cells using a non-transformed calvarial-derived cell line as model system for osteoblasts. In addition, the research investigated a possible interaction between GDNF and the multifunctional, pro-inflammatory cytokine, tumor necrosis factor- $\alpha$ (TNF- $\alpha$ ).

\section{Materials and methods}

\subsection{Cell cultures}

The MC3T3-E1 cell line is a non-transformed, clonal osteoblast-like cell line established from mouse calvaria and has extensively been used as a physiologically relevant in vitro model for calvarial osteoblasts, osteogenic differentiation and bone formation (15). MC3T3-E1 were acquired from the European Collection of Cell Cultures (ECACC) and were cultured in $\mathrm{AMEM}$ containing 10\% Fetal Bovine Serum (FBS), $1 \%$ penicillin/streptomycin, $200 \mathrm{mM}$ glutamine and $2.5 \mu \mathrm{g} / \mathrm{ml}$ Amphotericin B (Sigma Aldrich, UK) in a humidified $5 \% \mathrm{CO}_{2}$ incubator at $37^{\circ} \mathrm{C}$. Subconfluent cell cultures were trypsinised using Trypsin/EDTA (Gibco, UK) and plated into 96multiwell plates in $\alpha \mathrm{MEM} / 10 \% \mathrm{FBS}$ at 5,000 cells/well. After 24 hours, the cultures 
were replenished with either serum $(10 \%$ FBS $)$ or serum-free $\alpha$ MEM supplemented with $0.1 \%$ bovine serum albumin (BSA). Recombinant human GDNF (rhGDNF, provided by Amgen, Thousand Oaks, USA) or TNF- $\alpha$ (PeproTech, UK) was added to the cultures for a further two days. For the receptor inhibitor experiments, cultures were treated for 1 hour with different concentrations of phosphoinositide phopsholipase $\mathrm{C}$ (PI-PLC; Sigma) which blocks signalling via GFR $\alpha 1$ (16), or RPI-1 (Merck/Calbiochem), a specific RET receptor tyrosine kinase inhibitor (17), followed by further culture with the respective inhibitors in media with or without GDNF.

\subsection{Cell number and viability assays}

The WST1 assay (Roche Applied Biosciences) was used to assess the number of viable cells (18); the absorbance of the reduced compound was measured at a wavelength of 450 with a reference filter at $630 \mathrm{~nm}$ using a Biotek plate reader. The "live/dead" assay used $4 \mu \mathrm{M}$ acridine orange to stain nuclei of live cells and $4 \mu \mathrm{M}$ ethidium bromide to label nuclei of dead cells. The number of live and dead cells per microscopic field was counted under a Nikon Eclipse fluorescent microscope using 480 and 520nm filters, respectively. The level of cell death in the cultures was determined biochemically using a lactate dehydrogenase (LDH) cytotoxicity assay (Roche, UK). Cell culture supernatants were analysed after a 2-days' culture for the presence of LDH. Absorbance was determined at 490/630nm using the Biotek plate reader. 


\subsection{BrdU cell proliferation assay}

Cell proliferation was assessed using a 5-bromo-2-deoxy-uridine (BrdU) labeling and detection kit (Roche Applied Sciences). In brief, cells were labeled with $10 \mu \mathrm{M}$ BrdU for the final hour of the 48 hours' culture followed by fixation and immunostaining for BrdU incorporation using a specific anti-BrdU antibody. Cells were counterstained with hematoxylin and the total number of labeled and non-labeled nuclei were counted in 50 independent microscope fields.

\subsection{Biochemical alkaline phosphate (AlP) assay}

Cells were lysed in $0.1 \%$ Triton X-100 and incubated for $10 \mathrm{~min}$ in $1 \mathrm{M}$ diethanolamine buffer ( $\mathrm{pH}$ 9.8) containing $1 \mathrm{mg} / \mathrm{ml}$ p-nitrophenyl phosphate (pNPP) at $37^{\circ} \mathrm{C}$. Production of PNP (p-nitrophenol) was quantified spectrophotometrically at an absorbance of $405 \mathrm{~nm}$ using an automatic plate reader.

\subsection{Semi-quantitative RT-PCR (sqRT-PCR) analysis}

Cells were lysed in RLT buffer containing $\beta$-mercaptoethanol followed by RNA isolation using the RNeasy minikit (Qiagen, UK). Subsequently, $1 \mu \mathrm{g}$ of DNase-digested total RNA was used for oligo(dT) (Ambion, UK) reverse transcription to generate single-stranded cDNA using the Omniscript kit (Qiagen, UK). Centrifugal filters (Microcon) were used to purify and concentrate resultant cDNA. Both RNA and cDNA concentrations were determined from absorbance values at a wavelength of $260 \mathrm{~nm}$ using a BioPhotometer (Eppendorf, UK). sqRT-PCR assays were performed using the RedTaq PCR system (Sigma, UK) and the Mastercycler gradient thermal cycler 
(Eppendorf, UK). Primers were designed from NCBI mRNA sequences using Primer-3 design software (Table 1).

\subsection{Immunocytochemistry}

MC3T3-E1 were seeded onto multispot microscope slides and incubated for $24 \mathrm{~h}$ at 37 ${ }^{0} \mathrm{C}$ in a humidified $5 \% \mathrm{CO}_{2}$ incubator $(15,000$ cells/well). The adherent cells were fixed with ice-cold acetone for 5 min followed by rinsing in phosphate-buffered saline (PBS) containing 1\% BSA. Following incubation in $3 \% \mathrm{H}_{2} \mathrm{O}_{2}$ for 30 min (to block endogenous peroxidase), the slides were washed in PBS and incubated in $20 \%$ normal goat serum followed by incubation with $2 \mu \mathrm{g} / \mathrm{ml}$ primary polygonal rabbit antibody against GFR $\alpha 1$ (sc10716, SantaCruz) or against RET (sc167; SantaCruz) overnight at $4^{\circ} \mathrm{C}$. Both antibodies have been shown to specifically recognise the respective protein receptors as determined by immunoblotting, and have been validated for use in immunocytochemical staining of cell membrane receptors (see manufacturer's datasheets). To demonstrate that the immunocytochemical staining was specific for the primary antibody, the primary antibody was substituted with $20 \%$ normal rabbit serum. The slides were rinsed in $\mathrm{PBS} / 1 \% \mathrm{BSA}$ and labeled and stained with biotinstreptavidin-HRP using a Biogenex detection kit (LP000-UL). The slides were counterstained with haematoxylin before examination under a Zeiss microscope. 
Data obtained from the WST-1, LDH and ALP assays were corrected for background values and expressed as percentage of controls. Data were analysed using ANOVA with Tukey's posthoc test.

\section{Results}

\subsection{Expression of GDNF, GFR 1 and RET in calvarial osteoblasts}

sqRT-PCR analysis revealed that GDNF and its receptors GFR $\alpha 1$ and RET were expressed in the osteoblast cell line MC3T3-E1 (Fig. 1A). No obvious changes in gene expression were evident in serum-free cultures as compared to cultures maintained in serum supplemented media (Fig. 1A). This observation was supported by gel image analysis (unpublished observations). Immunocytochemical staining of MC3T3-E1 using specific antibodies against GFR $\alpha 1$ and RET confirmed the presence of these GDNF receptors (Fig. 1B).

\subsection{GDNF stimulates MC3T3-E1 cell proliferation}

Addition of GDNF to the osteoblast-like cells did not elicit major changes in the number of viable cells over a 2-day culture period in medium supplemented with FBS; however, at $100 \mathrm{ng} / \mathrm{ml}$ GDNF a significant, albeit modest decrease in cell number was evident ( $82.9 \%$ of controls). Conversely, GDNF dose-dependently increased viable MC3T3-E1 numbers in serum-free cultures (Fig. 2A). 
Biochemical analysis of alkaline phosphate (ALP), a non-specific marker for early osteoblast differentiation (19-20) demonstrated that GDNF had no significant effect on overall ALP activity (data not shown), but following correction for cell numbers a dosedependent decrease in ALP levels at increasing GDNF concentrations in serum-free cultures was evident (Fig. 2B). These data indicated that the reduced relative ALP activity in GDNF-treated serum-free cultures corresponded with increased cell growth.

To corroborate the WST-1 data, cell proliferation was further analyzed using the BrdUincorporation assay. The BrdU data demonstrated that the mitotic activity in serum-free cultures was greatly reduced compared to the serum-supplemented cultures (Fig. 3). GDNF had a modest, albeit non-significant, effect on BrdU labeling in serumcontaining cultures (23\% reduction compared to controls). However, GDNF significantly increased the number of BrdU-labeled cells in serum-free cultures by $103.7 \%$ (i.e. two-fold increase) demonstrating that GDNF stimulated cell replication under these conditions (Fig. 3).

\subsection{GDNF does not affect osteoblast cell survival}

To further investigate whether GDNF influenced cell survival, the live-dead assay was applied. Results demonstrated that significant cell death occurred in control, serum-free cultures as compared to serum-supplemented cultures (Fig. 4A). GDNF did not significantly affect the number of dead cells in either serum-containing or serum-free cultures suggesting that GDNF did not affect cell death or survival under either condition (Fig. 4A). 
These data were corroborated by the biochemical cytotoxicity LDH assay demonstrating that GDNF did not influence the level of cell death under serum-free conditions (Fig. 4B).

\subsection{Receptor-mediated effects of GDNF}

To determine whether GDNF affected the cells through its canonical receptors GFR $\alpha 1$ and RET, cultures were treated with specific compounds known to block GDNF signalling. PI-PLC which hydrolyses the GFR $\alpha 1$ subunits from their glycosylphosphatidylinositol (GPI)-anchored membrane proteins thereby negating GDNF signalling via this receptor, abrogated GDNF effects on viable cell numbers in serum-free cultures (Fig. 5). These data underline an essential role for GFR $\alpha 1$ in the GDNF effects on osteoblast viability. RPI-1, a competitive ATP-dependent RET kinase inhibitor, dose-dependently blocked GDNF action indicating that activation of the RET co-receptor was necessary to elicit GDNF signalling in these cells (Fig. 5).

\subsection{Interaction of GDNF with $T N F \alpha$}

Finally this study investigated the effects of GDNF in the presence of the proinflammatory cytokine TNF- $\alpha$, which is known to have profound effects on bone cells including MC3T3-E1 osteoblastic cells (21-23). TNF- $\alpha$ dose-dependently increased viable cell numbers in both serum-containing and serum-free MC3T3-E1 cultures (Fig. 6). Addition of GDNF to the cultures supplemented with TNF- $\alpha$ further promoted osteoblastic cell growth in these cultures: The stimulating effects of GDNF appeared 
relatively modest and non-significant in the 10\% FBS cultures (Fig. 6A); however, GDNF synergistically increased cell numbers in the presence of TNF- $\alpha$ in serum-free cultures (Fig. 6B).

\section{Discussion}

The current study provides evidence of a direct effect of GDNF on calvarial-derived osteoblasts suggesting a potential role for this neurotrophic factor in the regulation of craniofacial bone metabolism. GDNF as well as both of its canonical receptors GFR $\alpha 1$ and RET were shown to be expressed in MC3T3-E1 osteoblastic cells and signaling through both receptors was needed for GDNF effects on osteoblast cell growth. This is a novel and interesting finding, as previous studies reported that only GDNF and GFR $\alpha 1$ were present in two human osteosarcoma cell lines (Saos-2, MG63) and primary bone marrow stromal cells, but not RET (12). Thus this latter work had led to the conclusion that GDNF signaling in the bone marrow environment involved interaction with RET-expressing hematopoietic cells (13-14). Previous studies have suggested that isolated cells from calvarial bones may behave differently than osteoblasts derived from long bones ((21-23)), which may reflect the mechanistically different processes by which the different structures in the skeleton develop (i.e. flat bones via intramembranous bone formation, whereas long bones through the process of endochondral bone formation; (27)). Moreover, it is worth noting that a significant part of the craniofacial skeleton originates from neuronal crest "ecto-mesenchymal" progenitor cells and therefore the calvarial osteoblasts may therefore exhibit a different molecular repertoire and cell behavior than mesodermal/mesenchymal-derived boneforming cells present in long bones (24-26). RET is considered important for 
development and differentiation of neural crest-derived tissues, including cranial tissues (28-30). GDNF was shown to be co-expressed with GFR $\alpha 1 / 2$ and RET in dental epithelial and mesenchymal cells during tooth development $(31,32)$. Our recent studies indicated that mesenchymal/stromal cell cultures derived from dental pulp also displayed co-expression of GDNF and GFR $\alpha 1 /$ RET (33). RT-PCR analysis suggested that the calvarial osteoblasts expressed GDNF and the receptors GFR $\alpha 1$ and RET in serum-free cultures to a similar degree as cells maintained in serum-supplemented media.Previous studies demonstrated gene expression of both GDNF receptor components GFR $\alpha 1$ and RET in adrenal medullary cells and glial cells cultured in serum-free medium (34, 35).Interestingly, addition of serum upregulated the transcription levels of GFR $\alpha 1$ and RET in these cells $(34,35)$. Further quantitative RTPCR is recommended to evaluate and substantiate the effects of culture conditions on gene expression in osteoblasts; notwithstanding our observations indicate that the calvarial osteoblastic cell line expressing the primary GDNF receptors represents a suitable model to investigate GDNF signaling in either serum-containing or serum-free culture media.

This study demonstrates that GDNF stimulated MC3T3-E1 cell proliferation in serum-free conditions, which corresponded with a concomitant inhibitory effect on relative ALP activity, a marker of early osteogenic differentiation. Moreover, our data indicate that GDNF at high concentrations exerted a cell growth curbing effect on osteoblasts maintained in serum-supplemented culture medium; an effect that appeared to be associated with a slight increase in ALP activity (Fig. 2). It is well established that cell differentiation is often inversely related with mitotic activity and our observations indicate that GDNF effect on calvarial osteoblasts mainly involves an action on cellular 
proliferation with a concomitant inverse effect on immediate differentiation. Interestingly, GDNF/RET signaling has been shown to be responsible for the antimitotic action in an embryonic neural precursor carcinoma cell line (36). This effect mediated by $\mathrm{p} 27^{\mathrm{kip} 1}$ was suggested to be a mechanism by which GDNF regulates cell growth to initiate terminal differentiation (36). Long-term culture experiments will be required to investigate in further detail the role of GDNF in osteogenic proliferation, differentiation and bone formation.

The mitotic and cell survival actions of GDNF through GFR $\alpha 1 /$ RET signaling are well documented in the literature underscoring the multifunctional role of GDNF in tissue maintenance, repair and regeneration (1-3). Shi et al (37) described that GDNF promoted mesenchymal stem cell migration and survival; a mechanism by which GDNF may deliver renoprotection and kidney repair. The physiological implications of our findings that GDNF stimulated calvarial osteoblast proliferation under serum-deprived conditions are as yet unclear, but may allude to a novel role of this neurotrophic factor in bone remodeling and repair. GDNF is considered a member of the TGF $\beta$ superfamily as it has a partial amino-acid sequence homology and similar structural confirmation to TGF $\beta$ (38), which comprise growth factors including bone morphogenetic proteins pivotal in regulation of bone development, metabolism and repair. TGF $\beta 1$ can have diverse and multiple effects in different cell systems; notably this signaling molecule has been ascribed a central role in bone cell recruitment, proliferation and differentiation (39). Interestingly, TGF $\beta 1$ induces translocation of GFR $\alpha 1$ to the plasma membrane thereby enabling GDNF signaling through this receptor (40). It is also worth noting that GDNF is a potent inducer of the nuclear transcription factor, murine GDNF 
inducible factor (mGIF) which is homologous to the human TGF $\beta$ inducible early gene (TIEG) (41). TIEG expression which has been suggested to play a pivotal role in the regulation of osteoblast differentiation (42) is highly induced in human osteosarcoma cells as well as immortalized human fetal osteoblasts following treatment with TGF $\beta$ (43). It would be fascinating to explore whether GDNF signaling in calvarial osteoblasts is related to induction of TIEG/mGIF.

Considering that GDNF is produced by bone marrow stromal cells as well as osteoblasts $(9,44,45)$, it is tempting to speculate that GDNF in conjunction with other auto- and paracrine factors may be involved in the regulation of osteoblast recruitment in bone growth and remodelling. Indeed, this study demonstrated that GDNF cooperated with the cytokine TNF- $\alpha$ to stimulate osteoblastic cell growth suggesting an interaction between GDNF and TNF- $\alpha$ signalling pathways in osteoblasts. TNF- $\alpha$ has been ascribed a multifunctional role in bone metabolism (22); TNF- $\alpha$ effects may involve a proresorptive (osteoclastic bone degradation) action during inflammatory conditions (21), but TNF- $\alpha$ has also been recognised as an anabolic cytokine stimulating osteogenic migration, proliferation and differentiation (46-50). Interestingly, TNF- $\alpha$ has been shown to have neuroprotective capabilities which in part may be dependent on induction of cytoprotective neutrotrophic growth factors such as GDNF (51-53). Moreover TNF- $\alpha$ was reported to induce GDNF in chondrocytes underscoring a potential role for GDNF in skeletal cells under pro-inflammatory conditions (54). Further research is warranted to explore the precise role and mechanistic interaction of these pleiotrophic signaling molecules in bone remodeling and their potential therapeutic use in bone regeneration and repair. 
In conclusion, this is the first study to report that the neurotrophic factor GDNF is able to influence the proliferation of calvarial osteoblasts via its canonical receptors GFR $\alpha /$ RET expressed on these cells highlighting a novel regulatory pathway in craniofacial bone physiology.

\section{Acknowledgements}

This study was supported by a University of Birmingham School of Dentistry PhD research grant. We are grateful to Amgen Ltd (Thousands Oaks, USA) for the supply of the recombinant GDNF.

\section{References}

1. Airaksinen MS, Saarma M. The GDNF family: Signalling, biological functions and therapeutic value. Nature Reviews Neuroscience. 2002;3(5):383-94.

2. Paratcha G, Ledda F. GDNF and GFR alpha: a versatile molecular complex for developing neurons. Trends in Neurosciences. 2008;31(8):384-91.

3. Sariola H, Saarma M. Novel functions and signalling pathways for GDNF. Journal of Cell Science. 2003;116(19):3855-62.

4. Costantini F, Shakya R. GDNF/Ret signaling and the development of the kidney. Bioessays. [Review]. 2006 Feb;28(2):117-27.

5. Hellmich HL, Kos L, Cho ES, Mahon KA, Zimmer A. Embryonic expression of glial cell-line derived neurotrophic factor (GDNF) suggests multiple developmental roles in neural differentiation and epithelial-mesenchymal interactions. Mechanisms of Development. 1996;54(1):95-105.

6. Nosrat I, Seiger A, Olson L, Nosrat CA. Expression patterns of neurotrophic factor mRNAs in developing human teeth. Cell and Tissue Research. 2002;310(2):17787.

7. Chen Q, Long Y, Yuan XQ, Zou LL, Sun J, Chen SD, et al. Protective effects of bone marrow stromal cell transplantation in injured rodent brain: Synthesis of neurotrophic factors. Journal of Neuroscience Research. 2005;80(5):611-9. 
8. Gao YJ, Qian W, Wang BH, Lin R, Hou XH. Differentiation potential of bone marrow stromal cells to enteric neurons in vitro. Chin J Dig Dis. 2006;7(3):156-63.

9. Garcia R, Aguiar J, Alberti E, de la Cuetara K, Pavon N. Bone marrow stromal cells produce nerve growth factor and glial cell line-derived neurotrophic factors. Biochemical and Biophysical Research Communications. 2004;316(3):753-4.

10. Kurozumi K, Nakamura K, Tamiya T, Kawano Y, Ishii K, Kobune M, et al. Mesenchymal stem cells that produce neurotrophic factors reduce ischemic damage in the rat middle cerebral artery occlusion model. Molecular Therapy. 2005;11(1):96-104.

11. Li L, Lu G, Wang YF, Gao H, Xu X, Bai LH, et al. Glial cell-derived neurotrophic factor mRNA expression in a rat model of spinal cord injury following bone marrow stromal cell transplantation. Neural Regeneration Research. 2008;3(10):1056-9.

12. Gattei V, Celetti A, Cerrato A, Degan M, DeIuliis A, Rossi FM, et al. Expression of the RET receptor tyrosine kinase and GDNFR-alpha in normal and leukemic human hematopoietic cells and stromal cells of the bone marrow microenvironment. Blood. 1997;89(8):2925-37.

13. Gattei V, Degan M, Rossi FM, De Iuliis A, Mazzocco FT, Cesa E, et al. The RET receptor tyrosine kinase, but not its specific ligand, GDNF, is preferentially expressed by acute leukaemias of monocytic phenotype and is up-regulated upon differentiation. British Journal of Haematology. 1999;105(1):225-40.

14. Nakayama S, Iida $K$, Tsuzuki $T$, Iwashita $T$, Murakami H, Asai N, et al. Implication of expression of GDNF/Ret signalling components in differentiation of bone marrow haemopoietic cells. British Journal of Haematology. 1999;105(1):50-7.

15. Wang D, Christensen K, Chawla K, Xiao GZ, Krebsbach PH, Franceschi RT. Isolation and characterization of MC3T3-E1 preosteoblast subclones with distinct in vitro and in vivo differentiation mineralization potential. $\mathrm{J}$ Bone Miner Res. [Proceedings Paper]. 1999 Jun;14(6):893-903.

16. Krieglstein K, Henheik P, Farkas L, Jaszai J, Galter D, Krohn K, et al. Glial cell line-derived neurotrophic factor requires transforming growth factor-beta for exerting its full neurotrophic potential on peripheral and CNS neurons. Journal of Neuroscience. 1998;18(23):9822-34. 
17. Cuccuru G, Lanzi C, Cassinelli G, Pratesi G, Tortoreto M, Petrangolini G, et al. Cellular effects and antitumor activity of RET inhibitor RPI-1 on MEN2A-associated medullary thyroid carcinoma. J Natl Cancer Inst. [Article]. 2004 Jul;96(13):1006-14.

18. Scheven BA, Man J, Millard JL, Cooper PR, Lea SC, Walmsley AD, et al. VEGF and odontoblast-like cells: Stimulation by low frequency ultrasound. Archives of Oral Biology. 2009;54(2):185-91.

19. Scheven BAA, Vanderveen MJ, Damen CA, Lafeber F, Vanrijn HJM, Bijlsma JWJ, et al. EFFECTS OF METHOTREXATE ON HUMAN OSTEOBLASTS INVITRO - MODULATION BY 1,25-DIHYDROXYVITAMIN D-3. J Bone Miner Res. [Article]. 1995 Jun;10(6):874-80.

20. Wang H, Huo N, Li F, Fu S, Xue Y, Yang T, et al. Osteogenic role of endosomal chloride channels in MC3T3-E1 cells. Mol Cell Biochem. [; Research Support, Non-U.S. Gov't]. 20102010 Sep (Epub 2010 May;342(1-2):191-9.

21. Nanes MS.Tumor necrosis factor-alpha:molecualr and cellular mechanisms in skeletal pathology. Gene 2003; 321:1-15.

22. Robinson LJ, Borysenko $\mathrm{CW}$, Blair $\mathrm{HC}$,. tumor necrosis factor family receptors regualting bone turnover - new observations in osteoblastic and osteoclastic cell lines. Skeletal Biol Med 2007; 1116: 432-43

23. Yanga F, Abe M, Koga T, Hirata M. Signal transduction by tumor necrosis factor alpha is medicated through a guanine nucleotide-binding protein in osteoblast-like cellline, MC3T3-E1. J.Biol Chem 1992: 5114-21.

24. Declercq H, Van den Vreken N, De Maeyer E, Verbeeck R, Schacht E, De Ridder $\mathrm{L}$, et al. Isolation, proliferation and differentiation of osteoblastic cells to study cell/biomaterial interactions: comparison of different isolation techniques and source. Biomaterials. [Article]. 2004 Feb;25(5):757-68.

25. Rawlinson SCF, Mosley JR, Suswillo RFL, Pitsillides AA, Lanyon LE. CALVARIAL AND LIMB BONE-CELLS IN ORGAN AND MONOLAYERCULTURE DO NOT SHOW THE SAME EARLY RESPONSES TO DYNAMICMECHANICAL STRAIN. J Bone Miner Res. 1995;10(8):1225-32.

26. van den Bos T, Speijer D, Bank RA, Bromme D, Everts V. Differences in matrix composition between calvaria and long bone in mice suggest differences in 
biomechanical properties and resorption Special emphasis on collagen. Bone. [Article]. 2008 Sep;43(3):459-68.

27. Zins JE, Whitaker LA. MEMBRANOUS VERSUS ENDOCHONDRAL BONE - IMPLICATIONS FOR CRANIOFACIAL RECONSTRUCTION. Plastic and Reconstructive Surgery. 1983;72(6):778-84.

28. Edery P, Eng C, Munnich A, Lyonnet S. RET in human development and oncogenesis. Bioessays. [Review]. 1997 May;19(5):389-95.

29. Yan H, Bergner AJ, Enomoto H, Milbrandt J, Newgreen DF, Young HM. Neural cells in the esophagus respond to glial cell line-derived neurotrophic factor and neurturin, and are RET-dependent. Developmental Biology. [Article]. 2004 Aug;272(1):118-33.

30. Hashino E, Shero M, Junghans D, Rohrer H, Milbrandt J, Johnson EM. GDNF and neurturin are target-derived factors essential for cranial parasympathetic neuron development. Development. [Article]. 2001 Oct;128(19):3773-82.

31. Luukko K, Suvanto P, Saarma M, Thesleff I. Expression of GDNF and its receptors in developing tooth is developmentally regulated and suggests multiple roles in innervation and organogenesis. Developmental Dynamics. 1997;210(4):463-71.

32. Nosrat CA, Tomac A, Hoffer BJ, Olson L. Cellular and developmental patterns of expression of Ret and glial cell line-derived neurotrophic factor receptor alpha mRNAs. Experimental Brain Research. 1997;115(3):410-22.

33. Gale Z, Cooper PR, Scheven BAA. Effects of glial cell line derived neurotrophic factor on dental pulp cells.J.Dent Res 2011; 90:1240-5.

34.Forander P, Broberger C, Stromberg I. Glial cell line derived neurotrophic factor induces nerve fibre formation in primary cultures of adrenal chromaffin cells. Cell Tissue Res 2001; 305:43-51

35. remy S, Naveilhan $\mathrm{P}$, Brachet $\mathrm{P}$, Neveu I. Differential, regualtion of GDNF, neurturin and their receptors in primary cultures of rat glial cells. J. Neurosci Res; 64: $242-51$

36. Baldassarre G, Bruni P, Boccia A, Salvatore G, Melillo RM, Motti ML, et al. Glial cell line-derived neurotrophic factor induces proliferative inhibition of NT2/D1 cells through RET-mediated up-regulation of the cyclin-dependent kinase inhibitor p27(kip1). Oncogene. 2002;21(11):1739-49. 
37. Shi H, Patschan D, Dietz GPH, Baehr M, Plotkin M, Goligorsky MS. Glial cell line-derived neurotrophic growth factor increases motility and survival of cultured mesenchymal stem cells and ameliorates acute kidney injury. Am J Physiol-Renal Physiol. 2008;294(1):F229-F35.

38. Saarma M. GDNF - a stranger in the TGF-beta superfamily? European Journal of Biochemistry. 2000;267(24):6968-71.

39. Janssens K, ten Dijke P, Janssens S, Van Hul W. Transforming growth factorbeta 1 to the bone. Endocr Rev. [Review]. 2005 Oct;26(6):743-74.

40. Peterziel H, Unsicker K, Krieglstein K. TGF beta induces GDNF responsiveness in neurons by recruitment of GFR alpha 1 to the plasma membrane. Journal of Cell Biology. 2002;159(1):157-67.

41. Yajima S, Lammers CH, Lee SH, Hara Y, Mizuno K, Mouradian MM. Cloning and characterisation of murine glial cell line derived neurotrophic factor inducible transcription factor (mGIF). J. Neurosci 1997; 17(22):8657-66.

42. Subramaniam M, Gorny G, Johnsen SA, Monroe DG, Evans GL, Fraser DG, et al, TIEG1 null mouse-derived osteoblasts are defective in mineralisation and in support of osteoclast differentiation in vitro. Molec Cell Biol 2005; 25:1191-9

43. Hefferan TE, Subramaniam M, Khosla S, Riggs BL, Spelsberg TC. Cytokinespecific

induction of the TCF-beta inducible early gene (TIEG): regulation by specific members of the TGF-beta family. J Cell Biochem 2000;78:380-90.

44. Jiang JJ, Lv ZW, Gu YD, Li JF, Xu L, Xu WD, et al. Adult rat mesenchymal stem cells differentiate into neuronal-like phenotype and express a variety of neuroregulatory molecules in vitro. Neuroscience Research. 2010;66(1):46-52.

45. Kashani MHG, Tiraihi T, Ghorbanian MT, Abrari K. In Vitro Expression of BDNF, GDNF, NGF, NT3 and NT4/5 Genes in Selegiline Induced Bone Marrow Stromal Cells. Yakhteh. 2010;11(4):400-7.

46. Gowen M, Macdonald BR, Russell RGG. Actions of recombinant human gamma-interferon and tumor necrosis factor-alpha on the proliferation and osteoblastic characteristics of human trabecular bone-cells in vitro. Arth Rheum 1988;31:1500-7 
47. Frost A, Jonsson KB, Nilsson O, Ljunggren O. Inflammatory cytokines regulate proliferation of cultured human osteoblasts. Acta Orthop Scand. [Article]. 1997 Apr;68(2):91-6.

48. Glass GE, Chan JK, Freidin A, Feldmann M, Horwood NJ, Nanchahal J. TNFalpha promotes fracture repair by augmenting the recruitment and differentiation of muscle-derived stromal cells. Proceedings of the National Academy of Sciences of the United States of America. 2011;108(4):1585-90.

49. Lencel P, Delplace S, Hardouin P, Magne D. TNF-alpha stimulates alkaline phosphatase and mineralization through PPAR gamma inhibition in human osteoblasts. Bone. 2011;48(2):242-9.

50. Modrowski D, Godet D, Marie PJ. Involvement of interleukin 1 and Tumour Necrosis Factor [alpha] as endogenous growth factors in human osteoblastic cells. Cytokine. [doi: 10.1006/cyto.1995.0085]. 1995;7(7):720-6.

51. Figiel I. Pro-inflammatory cytokine TNF-alpha as a neuroprotective agent in the brain. Acta Neurobiol Exp. [Review]. 2008;68(4):526-34.

52. Kuno R, Yoshida Y, Nitta A, Nabeshima T, Wany J, Sonobe Y, et al. The role of TNF-alpha and its receptors in the production of NGF and GDNF by astrocytes. Brain Research. 2006;1116:12-8.

53. Frost A, Jonsson KB, Nilsson $\mathrm{O}$, Ljunggren $\mathrm{O}$. Inflammatory cytokines regulate proliferation of cultured human osteoblasts. Acta Orthop Scand 1997;68:91-6.

54. De Ceuninck F, Dassencourt L, Anract P. The inflammatory side of human chondrocytes unveiled by antibody microarrays. Biochem Biophys Res Commun 2004;323:960-9. 


\section{Tables and figures}

Table 1. PCR primer sequences and annealing temperature (Tm)

\begin{tabular}{|l|l|l|c|c|}
\hline $\begin{array}{l}\text { Gene } \\
\text { symbol }\end{array}$ & Primer sequence (5' to 3') & $\begin{array}{l}\text { Genbank } \\
\text { Accession no. }\end{array}$ & $\begin{array}{c}\text { Product } \\
\text { size }\end{array}$ & $\mathbf{T}_{\mathbf{m}}$ \\
\hline GAPDH & $\begin{array}{l}\text { F-CCCATCACCATCTTCCAGGAGC } \\
\text { R-CCAGTGAGCTTCCCGTTCAGC }\end{array}$ & NM017008 & $450 \mathrm{bp}$ & 60 \\
\hline GDNF & $\begin{array}{l}\text { F-AGAGGAATCGGCAGGCTGCAGCTG } \\
\text { R-AGATACATCCACATCGTTTAGCGG }\end{array}$ & NM019139 & $337 \mathrm{bp}$ & 60 \\
\hline RET & $\begin{array}{l}\text { F-TCAGGCATTTTGCAGCTATG } \\
\text { R-TGCAAAGGATGTGAAAGCAG }\end{array}$ & NM001110099 & $393 \mathrm{bp}$ & 62.5 \\
\hline GFR $\alpha 1$ & $\begin{array}{l}\text { F-AATGCAATTCAAGCCTTTGG } \\
\text { R-TGTGTGCTACCCGACACATT }\end{array}$ & U59486 & $218 \mathrm{bp}$ & 60 \\
\hline
\end{tabular}




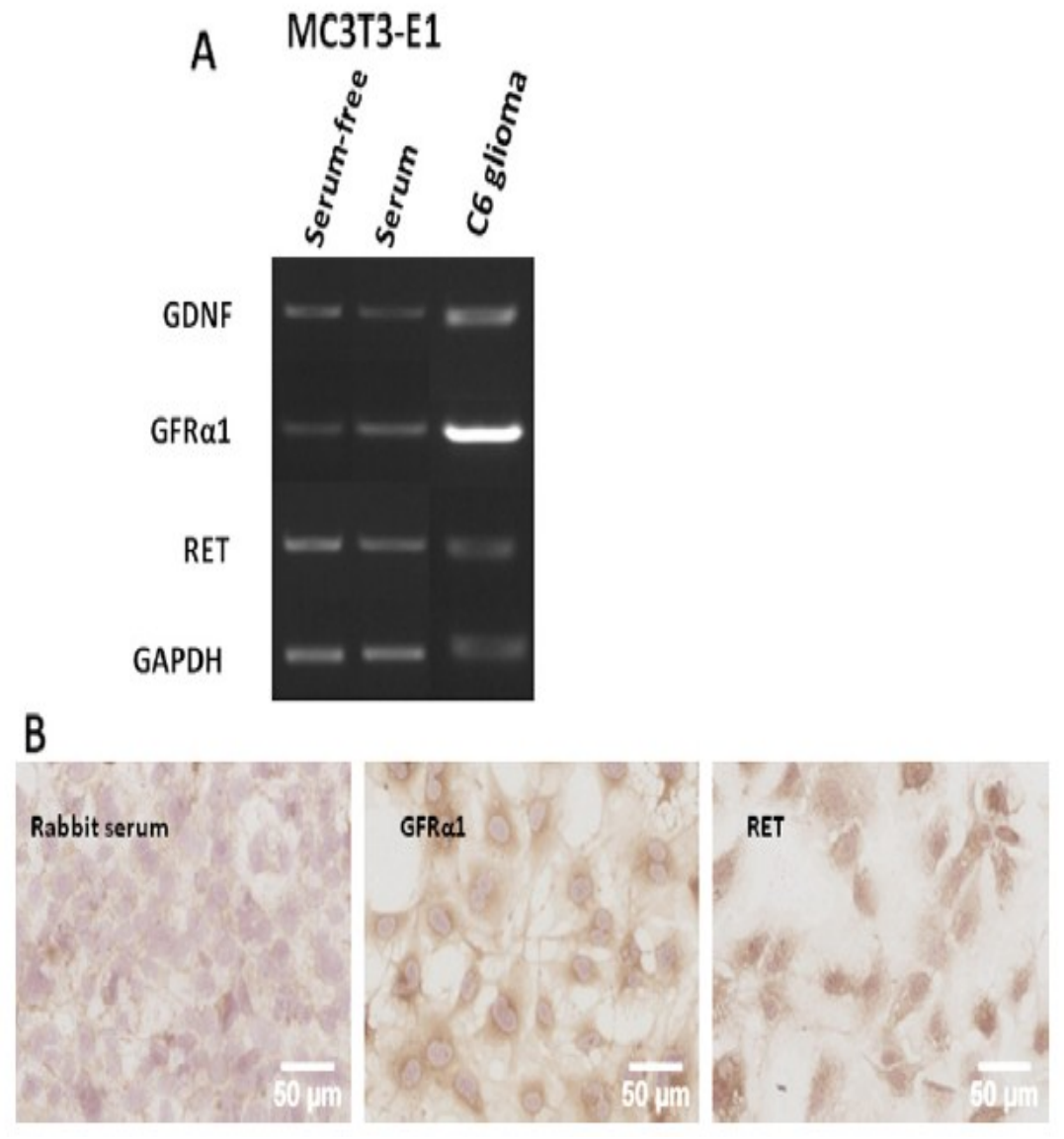

Fig. 1. (A) Representative RT-PCR gel images demonstrating the presence of transcripts for GDNF and its receptors GFRal and RET in MC3T3-E1 calvarial osteoblasts cultured

in serum-supplemented (10\% FBS) or serum-free culture medium for 2 days. C6 glioma cells were used as positive control, and glyceraldehyde-3-phosphate dehydrogenase (GAPDH) as control, housekeeping gene. Respective cycle number used for GDNF, GFRa1, RET and GAPDH were 35, 45, 45 and 25. (B) Immunocytochemical staining of MC3T3-E1 for GFRa1 and RET. Positive staining (brown) for both receptors was clearly evident in the MC3T3-E1 cells, whilst immunostaining was absent in controls (specific

primary antibody was substituted with non-immune rabbit serum). (For interpretation of the references to colour in this figure legend, the reader is referred to the web version of this article.) 

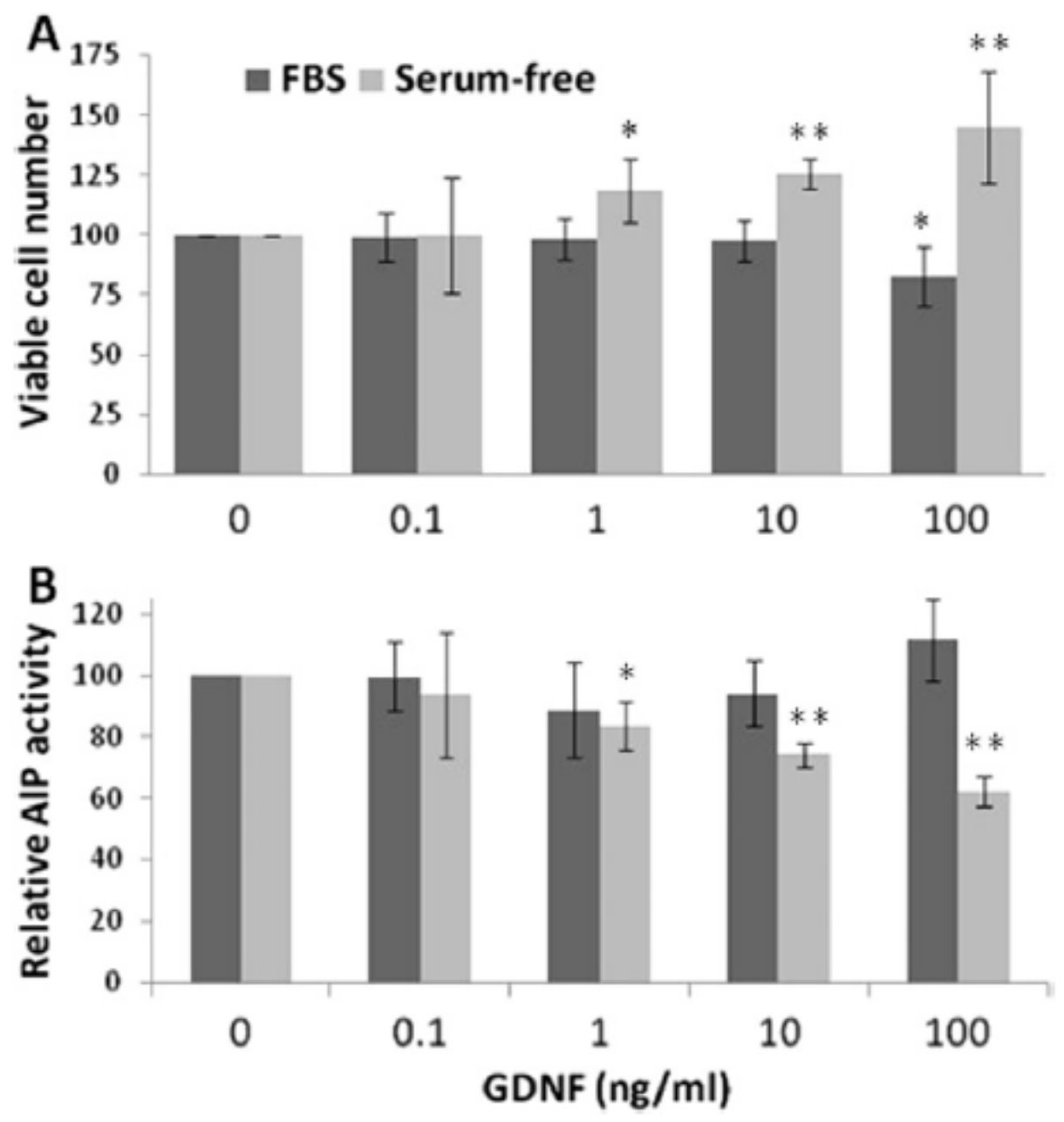

Fig. 2. (A) Effect of GDNF on viable MC3T3-E1 cell number in 2-day serum supplemented

$(10 \%$ FBS $)$ or serum-free $(0.1 \%$ BSA $)$ cultures as assessed by WST-1.

Results are expressed as percentage of controls (mean $\pm S D ; n=4)$. (B) Effect of GDNF on alkaline phosphatase (AIP) activity in osteoblast cultures after 2 days of culture. Results represent relative AlP activity corrected for cell number (percentage of controls; mean $\pm \mathrm{SD} ; \mathrm{n}=4) . / \mathrm{P}<0.05, / \mathrm{P}<0.01$ versus control values. 


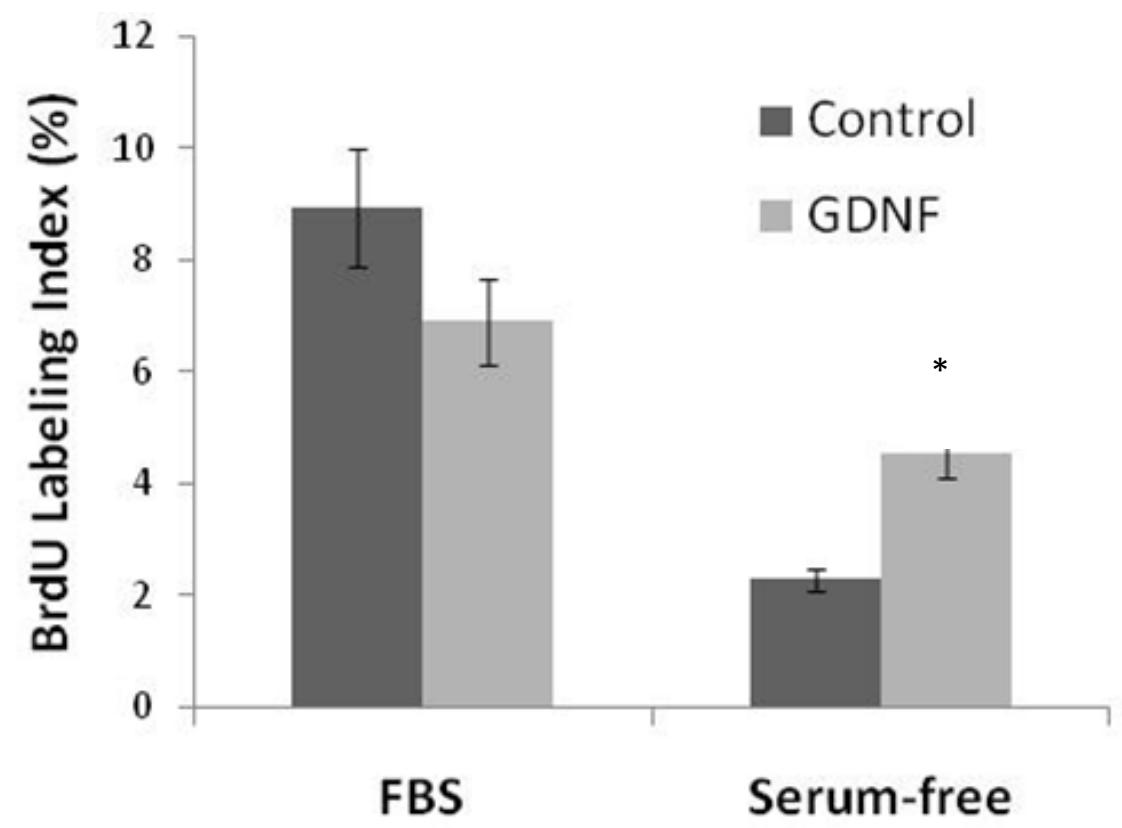

Fig. 3. BrdU incorporation in 2-day MC3T3-E1 cultures in serum-supplemented $(10 \% \mathrm{FBS})$ or serum-free $(0.1 \% \mathrm{BSA})$ cultures. The results show the proportion of cells labeled positively for BrdU (Li: labeling index). Significantly different from controls: $\mathbb{P}<0.05$. 

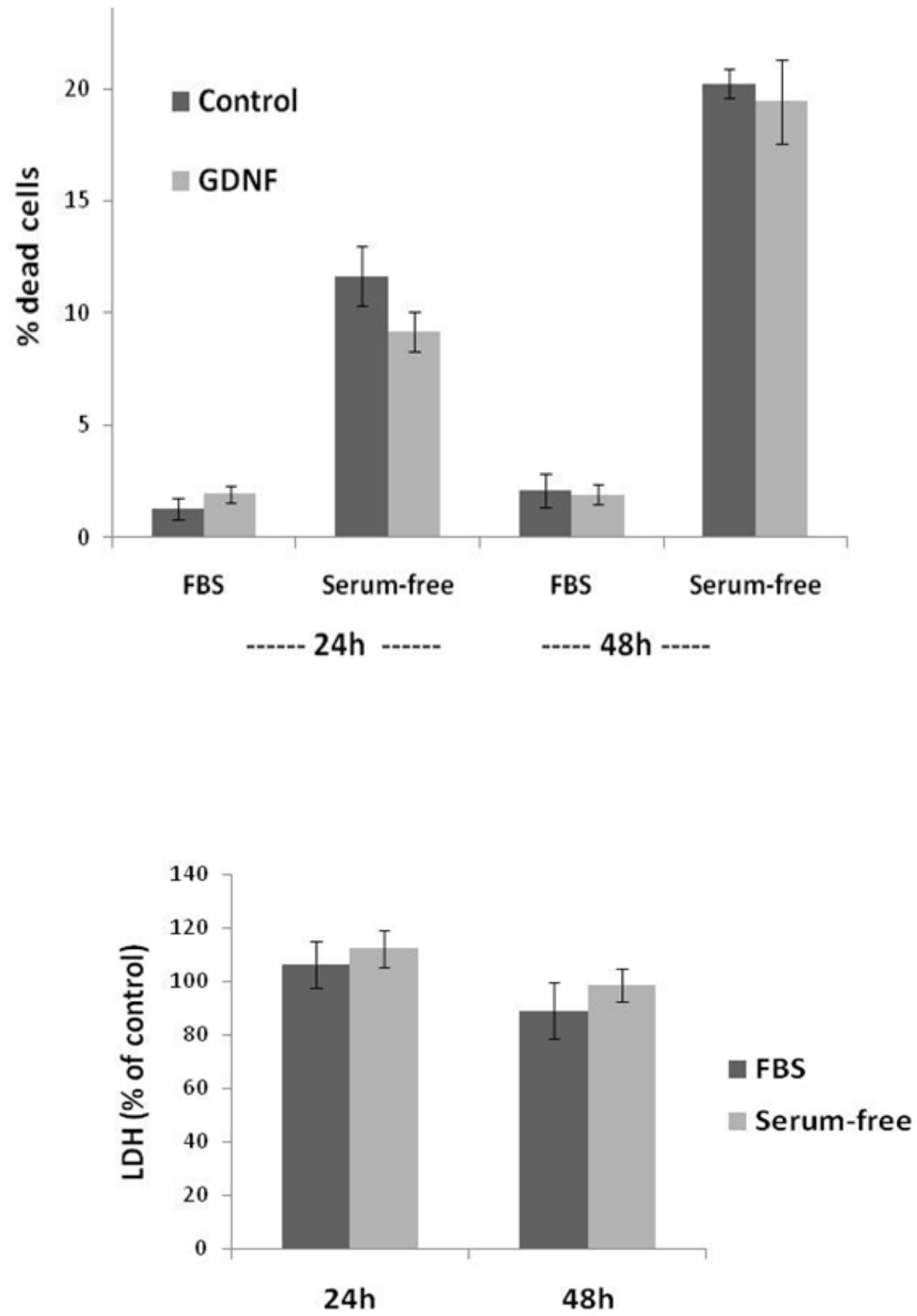

Fig. 4. Effects of GDNF on cell death in MC3T3-E1 cultures. (A) The number of dead cells as determined by the live/dead assay in cultures treated with $100 \mathrm{ng} / \mathrm{ml}$ GDNF. Results show percentage of dead cells in 1- and 2-day cultures (mean $\pm \mathrm{SD} ; \mathrm{n}=3$ ). (B) Relative LDH levels after 2-days culture in serum-containing or serum-free medium cultures supplemented with $100 \mathrm{ng} / \mathrm{ml}$ GDNF (mean $\pm \mathrm{SD} ; \mathrm{n}=3$ ). Results are mean $\pm \operatorname{SD}(n=3-4)$. 


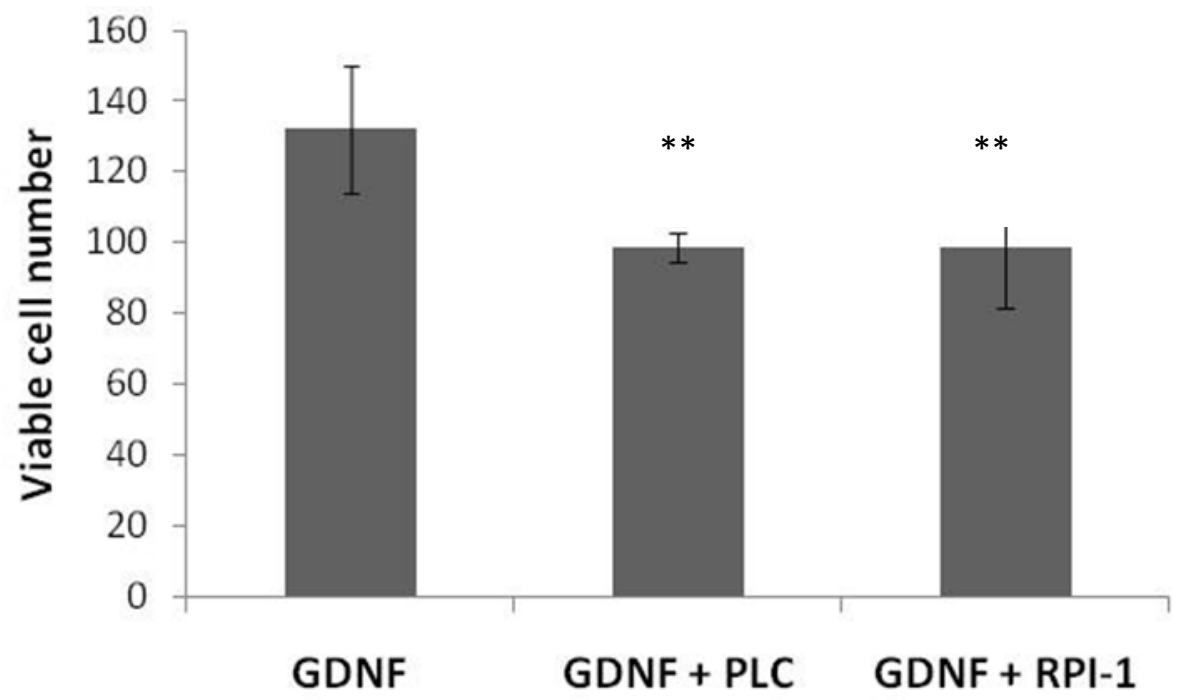

Fig. 5. Effects of GDNF receptor inhibitors on GDNF-stimulated MC3T3-E1 cultures. (A) Effect of phosphatidylinositol-specific phospholipase C (PLC) on viable cell number in cultures supplemented with $100 \mathrm{ng} / \mathrm{ml}$ GDNF. (B) Effects of the RET kinase inhibitor, RPI-1, on viable cell number in 2-day GDNF-treated cell cultures. Results are percentage of control values as determined by the WST1 assay (mean \} SD of 6.8 replicates). Data from GDNF control cultures (without inhibitor) were significantly different from controls without GDNF $(\mathrm{P}<0.01) \ldots \mathrm{P}<0.01$ versus GDNF cultures. 

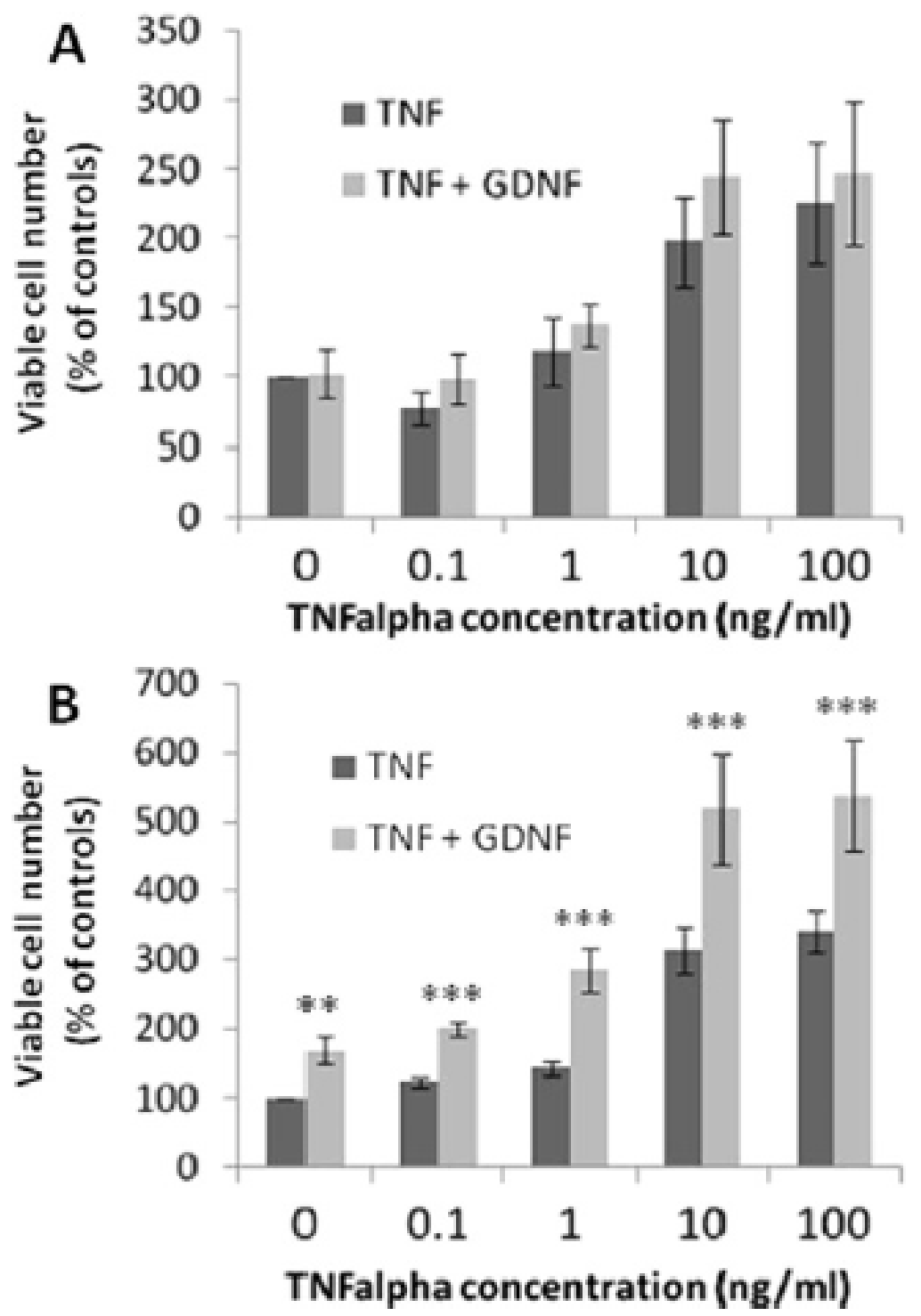

Fig. 6. Osteoblastic MC3T3-E1 cell numbers after 2-days' culture in the presence of increasing concentrations of TNF-a with or without $100 \mathrm{ng} / \mathrm{ml} \mathrm{GDNF}$ in media supplemented with $10 \%$ serum (A) or in serum-free cultures (B).Viable cell numbers were assessed using the WST-1 assay; results are expressed as percentage of controls (mean \pm SEM; $\mathrm{n}=3$ ). $/ \mathrm{P}<0.05, / / / \mathrm{P}<0.001$ GDNF-supplemented cultures versus corresponding TNF-a controls. 